\title{
ANALISIS PENGARUH PERSPEKTIF-PERSPEKTIF BALANCED SCORECARD TERHADAP KINERJA PERUSAHAAN PADA PERUSAHAAN DAERAH AIR MINUM KARANGANYAR
}

\author{
Endang Saryanti ${ }^{1}$, Erna Tiningrum ${ }^{2}$ \\ Sekolah Tinggi Ilmu Ekonomi Adi Unggul Bhirawa Surakarta \\ E-mail : endsary@gmail.com, ernatiningrum64@gmail.com
}

\begin{abstract}
ABSTRAK
Penelitian ini dilaksanakan untuk memberikan bukti bahwa perspektif-perspektif dalam balanced scorecard secara simultan dan parsial berpengaruh terhadap kinerja perusahaan pada Perusahaan Daerah Air Minum Karanganyar. Penelitian ini dilakukan dengan responden karyawan perusahaan dalam menilai kinerja perusahaan yang beralamatkan di Komplek Perkantoran Cangakan Karanganyar 57712. Populasi dalam penelitian ini 95 responden, tetapi hanya 88 sampel yang sempurna. Data dalam penelitian ini diperoleh melalui kuesioner yang dikirimkan pada responden penelitian dan data sekunder, yang diperoleh dari literature-literatur atau data yang mendukung.Teknik analisis data yang digunakan uji validitas, reliabilitas, analisis regrisi linier berganda, ujiasumsi klasik, uji t, uji F, dan koefisien determinasi. Hasil analisis regresi linier berganda menunjukan perspektif keuangan berpengaruh negatif terhadap kinerja perusahaan, perspektif pelanggan, proses bisnis internal, pembelajaran dan pertumbuhan berpengaruh positif terhadap kinerja perusahaan. Uji F yang dilakukan menunjukan terdapat pengaruh positif dan signifikan perspektif keuangan, perspektif pelanggan, perspektif proses bisnis internal, perspektif pembelajaran dan pertumbuhan secara simultan terhadap kinerja perusahaan pada PDAM Karanganyar. Hasil Uji t menunjukan perspektif keuangan berpengaruh negatif tidak signifikan terhadap kinerja Perusahaan Daerah Air Minum Karanganyar. Perspektif pelanggan berpengaruh positif tidak signifikan terhadap kinerja Perusahaan Daerah Air Minum Karanganyar. Perspektif proses bisnis internal berpengaruh positif signifikan terhadap kinerja Perusahaan Daerah Air Minum Karanganyar. Perspektif pembelajaran dan pertumbuhan berpengaruh positif tidak signifikan terhadap kinerja Perusahaan Daerah Air Minum Karanganyar. Hasil koefisien determinasi menunjukan bahwa perspektif keuangan, pelanggan, proses bisnis internal, pembelajaran dan pertumbuhan dapat menjelaskan kinerja perusahaan sebesar $26,4 \%$ dan sisanya dijelaskan oleh variabel lain yang tidak diteliti.
\end{abstract}

Kata Kunci: Kinerja Perusahaan,Perspektif Keuangan, Perspektif Pelanggan, Perspektif Proses Bisnis Internal Serta Perspektif,Pembelajaran Dan Pertumbuhan.

\section{PENDAHULUAN}

Dewasa ini pengukuran kinerja perusahaan menjadi hal yang sangat penting bagi manajemen untuk melakukan evaluasi terhadap performa perusahaan dan perencanaan tujuan dimasa mendatang. Berbagai informasi dihimpun agar pekerjaan yang dilakukan dapat dikendalikan dan dipertanggung jawabkan. Hal ini dilakukan untuk mencapai efisiensi dan efektivitas pada seluruh proses bisnis perusahaan.

Pengukuran itu penting, karena sistem pengukuran yang diterapkan perusahaan mempunyai dampak yang sangat besar dan berpengaruh terhadap perilaku manusia didalam maupun diluar organisasi. Perusahaan harus menggunakan sistem pengukuran dan manajemen yang diturunkan dari strategi dan kapabilitas yang dimiliki perusahaan agar berhasil dan tumbuh didalam persaingan abad informasi. Salah satu aspek pentingnya alat ukur kinerja perusahaan adalah bahwa alat ukur kinerja perusahaan dipakai oleh pihak manajemen sebagai dasar untuk melakukan pengambilan keputusan dan mengevaluasi kinerja manajemen serta unit terkait di 
lingkungan organisasi perusahaan. Begitu pula sebaliknya bagi organisasi, alat ukur ini dipakai oleh organisasi untuk melakukan koordinasi antara para manajer dengan tujuan dari masingmasing bagian yang nantinya akan memberikan kontribusi terhadap kemajuan dan keberhasilan perusahaan dalam mencapai sasarannya. Pengukuran kinerja perusahaan yang terlalu ditekankan pada sudut pandang finansial sering menghilangkan sudut pandang lain yang tentu saja tidak kalah pentingnya seperti, pengukuran kepuasan pelanggan dan proses adaptasi dalam suatu perubahan sehingga dalam suatu pengukuran kinerja, diperlukan suatu keseimbangan antara pengukuran kinerja finansial dan pengukuran kinerja non finansial.

Banyak metode yang telah dikembangkan untuk melakukan pengukuran kinerja suatu perusahaan. Dalam manajemen tradisional, ukuran kinerja yang biasa digunakan adalah ukuran keuangan. Hal ini disebabkan karena ukuran keuangan inilah yang paling mudah dideteksi, sehingga pengukuran kinerja personel juga diukur dengan dasar keuangan. Kinerja lain seperti peningkatan komitmen personel, peningkatan kompetensi dan lain sebagainya seringkali diabaikan. Dalam pendekatan Balanced Scorecard, pengukuran kinerja didasarkan pada aspek keuangan maupun non keuangan. Aspek nonkeuangan mendapat perhatian yang cukup serius karena pada dasarnya peningkatan kinerja keuangan bersumber dari aspek non keuangan yaitu peningkatan cost-effectiveness proses bisnis, peningkatan komitmen organisasi dan peningkatan kepercayaan customer terhadap produk yang dihasilkan, sehingga apabila perusahaan akan melakukan pelipatgandaan kinerja maka fokus perhatian perusahaan haruslah ditujukan kepada peningkatan kinerja di bidang non-keuangan karena dari situlah kinerja keuangan berasal. Pada sistem Balanced Scorecard ini data laporan finansial tetap dipertahankan sebagai salah satu faktor penting dalam mengukur kinerja, tetapi untuk lebih berhasil dimasa mendatang perlu melakukan investasi pada pelanggan, karyawan dan bisnis internal, sehingga informasi yang diberikan oleh data finansial diberikan tambahan melalui balanced scorecard yang memberikan faktor-faktor pemicu kinerja dimasa akan datang. Sayangnya, banyak perusahaan yang mencanangkan strategi tentang hubungan dengan pelanggan, kompetensi utama dan kapabilitas perusahaan ketika proses memotivasi dan mengukur kinerja masih dilaksanakan dengan menggunakan ukuran finansial ( Kaplan dan Norton, 1996).

Perusahaan harus mampu mempertahankan keberadaannya dalam peningkatan efektivitas kinerja perusahaan dengan meningkatkan pelayanan ataupun kualitas produk sehingga memiliki keunggulan kompetitif dibandingkan dengan perusahaan lain, yang dapat menarik minat konsumen agar selalu percaya serta dapat diandalkan mutunya. Setiap konsumen menginginkan kualitas produk dan layanan sesuai dengan kebutuhan dan harapan mereka. Dilihat dari segi pekerja, kita harus dapat memilih dan menyeleksi pekerja yang dikiranya mampu mengemban tugas dan berloyalitas tinggi terhadap perusahaan.

Perusahaan menerapkan metode BalancedScorecard dalam mengukur kinerja dan kualitas produk. Balanced Scorecard merupakan konsep manajemen yang diperkenalkan Robert Kaplan 1992, sebagai perkembangan dari konsep pengukuran kinerja yang mengukur perusahaan dengan menerapkan empat perspektif, yaitu perspektif finansial, pelanggan, proses bisnis internal, pertumbuhan dan pembelajaran. Balanced scorecard mengembangkan seperangkat tujuan unit bisnis melampaui rangkuman ukuran finansial. Balanced scorecard mencakup berbagai aktivitas penciptaan nilai yang dihasilkan oleh para partisipan perusahaan yang memiliki kemampuan dan motivasi tinggi, sementara tetap memperhatikan kinerja jangka pendek yaitu, melalui perspektif finansial. Balanced sorecard dengan jelas mengungkapkan berbagai faktor yang menjadi pendorong tercapainya kinerja finansial dan kompetitif jangka panjang yang superior. 
Berdasarkan uraian latar belakang tersebut, peneliti berkeinginan untuk mengadakan penelitian dengan judul "Analisis Pengaruh Perspektif-Perspektif Balanced Sorecard Terhadap Kinerja Perusahaan (studi kasus pada Perusahaan Daerah Air Minum Karanganyar)".

\section{TujuanPenelitian}

TujuanPenelitianadalahuntukmemberikanbuktiempirisbahwa:

1. Perspektiffinansial, pelanggan, proses bisnis internal serta pertumbuhan dan pembelajaran berpengaruh secara signifikan terhadap kinerja Perusahaan Daerah Air Minum Kabupaten Karangannyar secara simultan.

2. Perspektiffinansialberpengaruhsecarasignifikanterhadapkinerja Perusahaan Daerah Air MinumKabupatenKarangannyar.

3. Perspektifpelangganberpengaruhsecarasignifikanterhadapkinerja Perusahaan Daerah Air MinumKabupatenKarangannyar.

4. Perspektif proses bisnis internal berpengaruhsecarasignifikanterhadapkinerja Perusahaan Daerah Air MinumKabupatenKarangannyar.

\section{Kerangka Pemikiran}

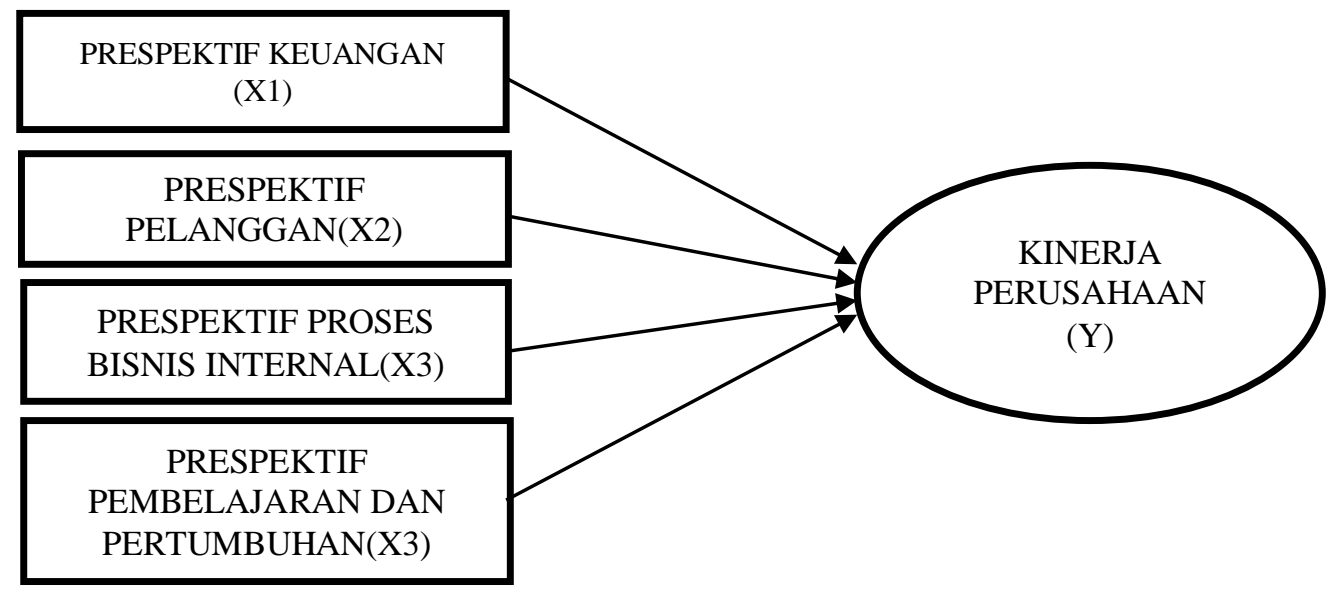

Sumber : Indriyati (2008)

\section{Hipotesis}

H1 : Perspektif finansial berpengaruh signifikan terhadap kinerja Perusahaan Daerah Air Minum Kabupaten Karanganyar.

H2 : Perspektif pelanggan berpengaruh signifikan terhadap kinerja Perusahaan Daerah Air Minum Kabupaten Karanganyar.

H3:Perspektif proses bisnis internal berpengaruh signifikan terhadap kinerja Perusahaan Daerah Air Minum Kabupaten Karanganyar.

H4 : Perspektif pertumbuhan dan pembelajaran berpengaruh signifikan terhadap kinerja Perusahaan Daerah Air Minum Kabupaten Karanganyar.

\section{Metode Penelitian}

Lokasi penelitian di Perusahaan Daerah Air Minum Karanganyar. Populasi dalam penelitian ini adalah karyawan yang bekerja di Perusahaan Daerah Air Minum Karanganyar dengan jumlah keseluruhan dari karyawan pusat dan cabang-cabangnya berjumlah 210 karyawan. Sampel yang 
Excellent : Jurnal Manajemen, Bisnis dan Pendidikan

Vol 7, No 1 (2020) ; p.25-36; https://e-journal.stie-aub.ac.id/index.php/excellent

akan diambil hanya dari pusat dan sebagian dari cabang sebesar 95 karyawan. Teknik pengambilan sampel menggunakan metode acak. Metode analisis dengan uji validitas, uji rentabilitas, uji normalitas, uji heteroskedastisitas, uji multikolinieritas, uji regresi linier berganda, uji t, uji $\mathrm{F}$ dan uji koefisien determinasi.

\section{Hasil dan Pembahasan}

\section{Tabel 1}

Hasil Uji Validitas Perspektif Keuangan (X1)

\begin{tabular}{|l|l|l|l|l|}
\hline Item Pertanyaan & r hitung & r tabel & signifikansi & keterangan \\
\hline x1_1 & 0,575 & 0,2072 & 0,000 & Valid \\
\hline x1_2 & 0,775 & 0,2072 & 0,000 & Valid \\
\hline x1_3 & 0,703 & 0,2072 & 0,000 & Valid \\
\hline x1_4 & 0,849 & 0,2072 & 0,000 & Valid \\
\hline x1_5 & 0,786 & 0,2072 & 0,000 & Valid \\
\hline x1_6 & 0,604 & 0,2072 & 0,000 & Valid \\
\hline x1_7 & 0,701 & 0,2072 & 0,000 & Valid \\
\hline
\end{tabular}

Sumber: Data yang diolah, 2017

\section{Tabel 2}

Hasil Uji Validitas Perspektif Pelanggan (X2)

\begin{tabular}{|l|l|l|l|l|}
\hline Item Pertanyaan & $\mathrm{r}$ hitung & $\mathrm{r}$ tabel & signifikansi & keterangan \\
\hline $\mathrm{x} 2 \_1$ & 0,750 & 0,2072 & 0,000 & Valid \\
\hline $\mathrm{x} 2 \_2$ & 0,712 & 0,2072 & 0,000 & Valid \\
\hline $\mathrm{x} 2 \_3$ & 0,816 & 0,2072 & 0,000 & Valid \\
\hline $\mathrm{x} 2 \_4$ & 0,803 & 0,2072 & 0,000 & Valid \\
\hline $\mathrm{x} 2 \_5$ & 0,770 & 0,2072 & 0,000 & Valid \\
\hline $\mathrm{x} 2 \_6$ & 0,798 & 0,2072 & 0,000 & Valid \\
\hline $\mathrm{x} 2 \_7$ & 0,787 & 0,2072 & 0,000 & Valid \\
\hline $\mathrm{x} 2 \_8$ & 0,759 & 0,2072 & 0,000 & Valid \\
\hline
\end{tabular}

Sumber: Data yang diolah, 2017

\section{Tabel 3}

Hasil Uji Validitas Perspektif Proses Bisnis Internal (X3)

\begin{tabular}{|l|l|l|l|l|}
\hline Item Pertanyaan & r hitung & r tabel & signifikansi & keterangan \\
\hline x3_1 & 0,621 & 0,2072 & 0,000 & Valid \\
\hline x3_2 & 0,712 & 0,2072 & 0,000 & Valid \\
\hline X3_3 & 0,336 & 0,2072 & 0,001 & Valid \\
\hline x3_4 & 0,786 & 0,2072 & 0,000 & Valid \\
\hline x3_5 & 0,431 & 0,2072 & 0,000 & Valid \\
\hline x3_6 & 0,718 & 0,2072 & 0,000 & Valid \\
\hline
\end{tabular}

Sumber: Data yang diolah, 2017 


\section{Vol 7, No 1 (2020) ; p.25-36; https://e-journal.stie-aub.ac.id/index.php/excellent}

\section{Tabel 4}

\section{Hasil Uji Validitas}

Perspektif Pembelajaran dan Pertumbuhan (X4)

\begin{tabular}{|l|l|l|l|l|}
\hline Item Pertanyaan & r hitung & r tabel & signifikansi & keterangan \\
\hline x4_1 & 0,788 & 0,2072 & 0,000 & Valid \\
\hline x4_2 & 0,536 & 0,2072 & 0,000 & Valid \\
\hline x4_3 & 0,709 & 0,2072 & 0,000 & Valid \\
\hline x4_4 & 0,542 & 0,2072 & 0,000 & Valid \\
\hline x4_5 & 0,802 & 0,2072 & 0,000 & Valid \\
\hline
\end{tabular}

Sumber: Data yang diolah, 2017

\section{Tabel 5}

Hasil Uji Validitas Kinerja Perusahaan (Y)

\begin{tabular}{|l|l|l|l|l|}
\hline Item Pertanyaan & r hitung & r tabel & signifikansi & keterangan \\
\hline y_1 & 0,578 & 0,2072 & 0,000 & Valid \\
\hline y_2 & 0,661 & 0,2072 & 0,000 & Valid \\
\hline y_3 & 0,729 & 0,2072 & 0,000 & Valid \\
\hline y_4 & 0,572 & 0,2072 & 0,000 & Valid \\
\hline y_5 & 0,490 & 0,2072 & 0,000 & Valid \\
\hline
\end{tabular}

Sumber: Data yang diolah, 2017

\section{Tabel 6}

Hasil Uji Reliabilitas Variabel Penelitian

\begin{tabular}{|l|l|l|l|}
\hline Variabel Penelitian & $\begin{array}{l}\text { Alpha } \\
\text { cronbach's }\end{array}$ & $\begin{array}{l}\text { Alpha } \\
\text { kriteria }\end{array}$ & Keterangan \\
\hline Perspektif keuangan (X1) & 0,839 & 0,60 & Reliabel \\
\hline Perspektif pelanggan (X2) & 0,901 & 0,60 & Reliabel \\
\hline Perspektif Proses bisnis internal (X3) & 0,633 & 0,60 & Reliabel \\
\hline Pp. pembelajaran dan pertumbuhan (X4) & 0,710 & 0,60 & Reliabel \\
\hline Kinerja perusahaan (Y) & 0,719 & 0,60 & Reliabel \\
\hline
\end{tabular}

Sumber: Data yang diolah, 2017

\section{Tabel 7}

Hasil Uji Normalitas

\section{One-Sample Kolmogorov-Smirnov Test}

\begin{tabular}{|ll|l|}
\hline & & $\begin{array}{l}\text { Unstandardized } \\
\text { Residual }\end{array}$ \\
\hline $\mathrm{N}$ & & 88 \\
Normal Parameters(a,b) & Mean &, 0000000 \\
& Std. Deviation & 2,28222570 \\
Most Extreme Differences & Absolute &, 067 \\
& Positive &, 067 \\
& Negative &,- 064 \\
Kolmogorov-Smirnov Z & &, 628 \\
Asymp. Sig. (2-tailed) & &, 825 \\
\hline a Test distribution is Normal. & & \\
b Calculated from data & & \\
Sumber: Print out SPSS &
\end{tabular}




\section{Tabel 8}

Hasil Uji Multikolinieritas

Coefficients(a)

\begin{tabular}{|ll|l|l|}
\hline \multicolumn{2}{|l|}{} & \multicolumn{2}{|c|}{ Collinearity Statistics } \\
\cline { 1 - 1 } & & Tolerance & VIF \\
\hline 1 & (Constant) & & \\
& p_keugn &, 467 & 2,139 \\
& p_plgn &, 583 & 1,716 \\
& p_bi &, 553 & 1,807 \\
& p_pp &, 448 & 2,230 \\
\hline
\end{tabular}

a Dependent Variable: kinerja

Sumber: Print out SPSS

Hasil uji melalui Variance inflation factor (VIF) yang terlihat dalam output SPSS, masing-masing variabel independen memiliki nilai VIF $<10$ dan nilai tolerance $>0,1$, maka dapat dinyatakan model regresi linier berganda terbebas dari multikolonieritas dan dapat digunakan dalam penelitian.

\section{Uji Heteroskedastisitas}

Hasil uji heteroskedastisitas dapat dilihat dalam bentuk gambar sebagai berikut:

\section{Gambar 1}

\section{Hasil Uji Heteroskedastisitas}

Scatterplot

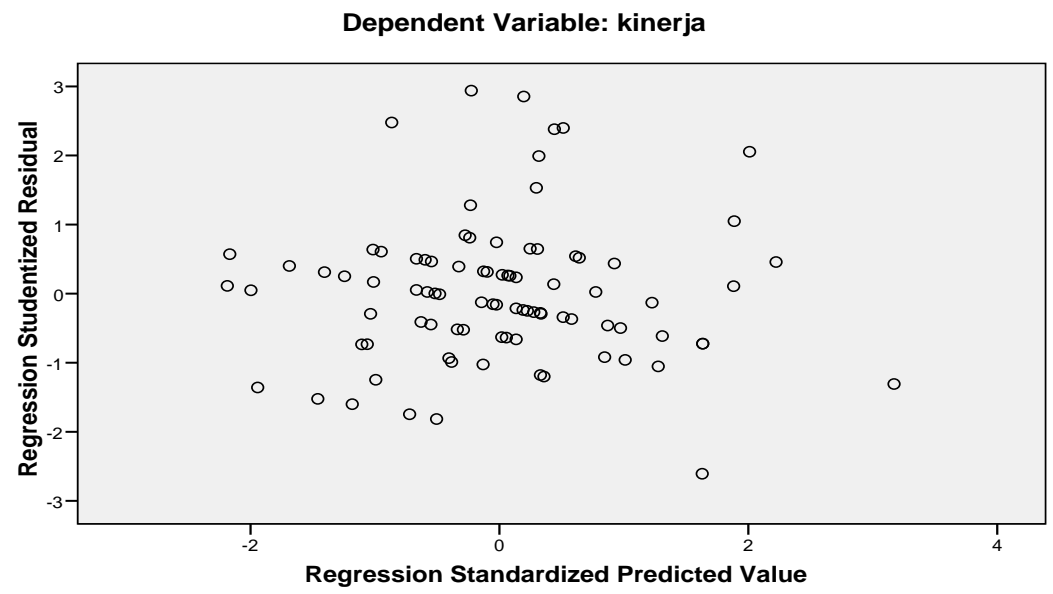

Berdasarkan pada grafik tersebut terlihat bahwa titik-titik menyebar secara acak serta tersebar baik diatas maupun dibawah angka 0 pada sumbu Y dan tidak membentuk pola tertentu, hal ini dapat disimpulkan bahwa tidak terjadi heteroskedastisitas pada model regresi layak dipakai untuk memprediksi $\mathrm{Y}$ berdasarkan masukan variabel independen $\mathrm{X} 1, \mathrm{X} 2, \mathrm{X} 3, \mathrm{X} 4$.

\section{Analisis Regresi Linier Berganda}

Analisis regresi linier berganda diperoleh hasil yang terlihat dalam tabel sebagai berikut: 


\section{Tabel 9}

Hasil Analisis Regresi linier berganda

\section{Coefficients(a)}

\begin{tabular}{|cl|l|l|l|l|}
\hline \multicolumn{2}{|l|}{} & \multicolumn{2}{|l|}{$\begin{array}{l}\text { Unstandardized } \\
\text { Model }\end{array}$} & $\mathrm{t}$ & Sig. \\
\hline & & $\mathrm{B}$ & Std. Error & $\mathrm{B}$ & Std. Error \\
\hline (Constant) & 6,612 & 2,541 & 2,602 &, 011 \\
p_keugn &,- 164 &, 108 & $-1,520$ &, 132 \\
p_plgn &, 141 &, 076 & 1,861 &, 066 \\
p_bi &, 364 &, 126 & 2,879 &, 005 \\
p_pp &, 215 &, 141 & 1,529 &, 130 \\
\hline
\end{tabular}

a Dependent Variable: kinerja

Sumber: Print out SPSS

Hasil yang terdapat dalam tabel IV. 16 tersebut dapat uraikan sebagai berikut:

1.Persamaan Regresi Linier Berganda

Persamaan regresi Linier berganda yang dihasilkan adalah sebagai berikut:

$\mathrm{Y}=6,612-0,164 \mathrm{X} 1+0,141 \mathrm{X} 2+0,364 \mathrm{X} 3+0,215 \mathrm{X} 4$

2. Interprestasi Persamaan Regrasi Linier Berganda

Berdasarkan pada persamaan tersebut, maka dapat diinterprestasikan sebagai berikut:

a. $a=6,612$, artinya apabila perspektif keuangan (X1), perspektif pelanggan (X2), perspektif proses bisnis internal (X3), perspektif pembelajaran dan pertumbuhan (X4), adalah sama dengan nol, maka kinerja perusahaan (Y) pada Perusahaan Daerah Air Minum Karanganyar yang dihasilkan adalah positif.

b. $b_{1}=-0,164$, artinya perspektif keuangan (X1) berpengaruh negatif terhadap kinerja perusahaan (Y) pada PDAM Karanganyar.

c. $b_{2}=0,141$, artinya perspektif pelanggan (X2) berpengaruh positif terhadap kinerja perusahaan (Y) pada PDAM Karanganyar.

d. $b_{3}=0,364$, artinya perspektif proses bisnis internal (X3) berpengaruh positif terhadap kinerja perusahaan (Y) pada PDAM Karanganyar.

e. $b_{4}=0,215$, artinya perspektif pembelajaran dan pertumbuhan (X4) berpengaruh positif terhadap kinerja perusahaan (Y) pada PDAM Karanganyar.

\section{Pengujian Hipotesis}

1. Uji F

Hasil uji F dalam penelitian ini dapat dilihat dalam bentuk tabel sebagai berikut: 


\section{Tabel 10}

Hasil Uji F

$\operatorname{ANOVA}(\mathbf{b})$

\begin{tabular}{|ll|l|l|l|l|l|}
\hline \multicolumn{2}{|l|}{ Model } & $\begin{array}{l}\text { Sum of } \\
\text { Squares }\end{array}$ & df & Mean Square & F & Sig. \\
\hline 1 & Regression & 192,129 & 4 & 48,032 & 8,798 &, $000(\mathrm{a})$ \\
& Residual & 453,144 & 83 & 5,460 & & \\
& Total & 645,273 & 87 & & & \\
\hline
\end{tabular}

a Predictors: (Constant), p_pp, p_plgn, p_bi, p_keugn

b Dependent Variable: kinerja

Sumber: Print out SPSS

\section{Nilai $\mathbf{F}_{\text {hitung }}$}

Ho diterima apabila $\mathrm{F}_{\text {hitung }} \leq 3,9560$

Ho ditolak apabila $F_{\text {hitung }}>3,9560$

Berdasarkan analisa yang telah dilakukan diperoleh nilai $\mathrm{F}_{\text {hitung }} 8,798>$ nilai $\mathrm{F}_{\text {tabel }} 3,9560$ atau dilihat dari nilai signifikansi $0,000<0,05$, maka Ho ditolak yang berarti berpengaruh positif dan signifikan perspektif keuangan (X1), perspektif pelanggan (X2), perspektif proses bisnis internal (X3), perspektif pembelajaran dan pertumbuhan (X4) secara simultan terhadap kinerja perusahaan (Y) pada PDAM Karanganyar.

\section{Tabel 11}

Hasil Uji t

Hasil analisis dengan menggunakan uji t dapat dilihat dalam bentuk tabel sebagai berikut:

\section{Coefficients(a)}

\begin{tabular}{|ll|l|l|}
\hline Model & & $\mathrm{t}$ & Sig. \\
\hline & & $\mathrm{B}$ & Std. Error \\
\hline & (Constant) & 2,602 &, 011 \\
p_keugn & $-1,520$ &, 132 \\
p_plgn & 1,861 &, 066 \\
p_bi & 2,879 &, 005 \\
p_pp & 1,529 &, 130 \\
\hline
\end{tabular}

a Dependent Variable: kinerja,

\section{Sumber: print out SPSS}

\section{Nilai $\mathbf{T}_{\text {hitung }}$}

Ho diterimaapabila $-1,6634 \leq \mathrm{t}_{\text {hitung }} \leq 1,6634$

Ho ditolakapabilat ${ }_{\text {hitung }}>1,6634$ ataut $_{\text {hitung }}<-1,6634$

Hasil uji t yang telah dilakukan diperoleh nilai-nilai $t_{\text {hitung }}$ yang terlihat dalam tabel IV. 18 adalah sebagai berikut: 
1) Variabel perspektif keuangan (X1) diperoleh nilai $t_{\text {hitung }}-1,520<$ nilai $t_{\text {tabel }}$ 1,6634 atau dilihat dari nilai signifikan $0,132>0,05$, maka Ho diterima yang berarti berpengaruh negatif tidak signifikan perspektif keuangan (X1) terhadap kinerja perusahaan (Y) pada Perusahaan Daerah Air Minum Karanganyar.

2) Variabel perspektif pelanggan $(\mathrm{X} 2)$ diperoleh nilai $t_{\text {hitung }} 1,861>$ nilai $t_{\text {tabel }}$ 1,6634 atau dilihat dari nilai signifikan $0,066>0,05$, maka Ho diterima yang berarti berpengaruh positif tidak signifikan perspektif pelanggan (X2) terhadap kinerja perusahaan (Y) pada Perusahaan Daerah Air Minum Karanganyar.

3) Variabel perspektif proses bisnis internal diperoleh nilai $t_{\text {hitung }} 2,879>$ nilai $t_{\text {tabel }}$ 1,6634 atau dilihat dari nilai signifikan $0,005<0,05$, maka Ho ditolak yang berarti berpengaruh positif dan signifikan perspektif proses bisnis internal (X3) terhadap kinerja perusahaan (Y) pada Perusahaan Daerah Air Minum Karanganyar.

4) Variabel perspektif pembelajaran dan pertumbuhan diperoleh nilai thitung 1,529 $<$ nilai $t_{\text {tabel }}$ 1,6634 atau dilihat dari nilai signifikan 0,130>0,05, maka Ho diterima yang berarti berpengaruh positif tidak signifikan perspektif permbelajaran dan pertumbuhan (X4) terhadap kinerja perusahaan (Y) pada Perusahaan Daerah Air Minum Karanganyar.

\section{Koefisien Determinasi}

\section{Tabel 12}

Hasil Analisis Koefisien Determinasi

\section{Model Summary}

\begin{tabular}{|l|l|l|l|l|}
\hline Model & R & R Square & $\begin{array}{l}\text { Adjusted R } \\
\text { Square }\end{array}$ & $\begin{array}{l}\text { Std. Error of } \\
\text { the Estimate }\end{array}$ \\
\hline 1 & ,546(a) &, 298 &, 264 & 2,33657 \\
\hline
\end{tabular}

a Predictors: (Constant), p_pp, p_plgn, p_bi, p_keugn

b Dependent Variable: kinerja

Sumber: Print out SPSS

Hasil perhitungan diperoleh nilai yang positif dari $\mathrm{R}^{2}$ (adjusted $R$ square), yaitu 0,264 yang artinya bahwa sumbangan yang diberikan variable bebas yang berupa perspektif keuangan (X1), perspektif pelanggan (X2), perspektif proses bisnis internal (X3), pespektif pembelajaran dan pertumbuhan (X4) terhadap kinerja perusahaan (Y) pada Perusahaan Daerah Air Minum Karanganyar adalah sebesar 0,264 atau 26,4\%, sedangkan sisanya $(100 \%-26,4 \%)=73,6 \%$ dipengaruhi oleh variabel bebas lain yang tidak diteliti.

\section{A. Kesimpulan}

Kesimpulan yang diperoleh dari pelaksanaan penelitian ini adalah sebagai berikut:

1. Berdasarkan hasil analisis regresi linier linier berganda, menunjukan bahwa variabel perspektif keuangan berpengaruh negatif pada kinerja Perusahaan Daerah Air Minum Karanganyar, dan perspektif pelanggan, perspektif proses bisnis internal, perspektif pembelajaran dan pertumbuhan berpengaruh positif terhadap kinerja Perusahaan Daerah Air Minum Karanganyar. 
2. Berdasarkan hasil uji $\mathrm{F}$ yang telah dilakukan menunjukan bahwa secara simultan variabel perspektif keuangan (X1), perspektif pelanggan (X2), perspektif proses bisnis internal (X3), perspektif pembelajaran dan pertumbuhan (X4) berpengaruh positif dan signifikan terhadap kinerja perusahaan (Y) pada PDAM Karanganyar.

3. Berdasarkan uji t yang telah dilakukan menunjukan hasil sebagai berikut:

a. Variabel perspektif keuangan (X1) berpengaruh negative tidak signifikan terhadap kinerja perusahaan (Y) pada Perusahaan Daerah Air Minum Karanganyar. Variabel perspektif ini tidak mendukung penelitian Indriyati.

b. Variabel perspektif pelanggan (X2) berpengaruh positif tidak signifikan terhadap kinerja perusahaan (Y) pada Perusahaan Daerah Air Minum Karanganyar. Variabel Perspektif ini tidak mendukung penelitian Indriyati.

c. Variabel perspektif proses bisnis internal berpengaruh positif dan signifikan terhadap kinerja perusahaan (Y) pada Perusahaan Daerah Air Minum Karanganyar. Variabel Perspektif ini mendukung penelitian Indriyati.

d. Variabel perspektif pembelajaran dan pertumbuhan berpengaruh positif tidak signifikan terhadap kinerja perusahaan (Y) pada Perusahaan Daerah Air Minum Karanganyar. Variabel Perspektif ini tidak mendukung penelitian Indriyati.

4. Koefisien determinasi menunjukan persentase pengaruh yang diberikan variabel independen berupa variabel perspektif keuangan, perspektif pelanggan, perspektif proses bisnis internal, serta perspektif pembelajaran dan pertumbuhan terhadap kinerja Perusahaan Daerah Air Minum Karanganyar sebesar 0,264 atau 26,4\%.

5. Penelitian yang telah dilaksanakan diperoleh hasil yang dapat menjawab hipotesis bahwa secara simultan, perspektif-perspektif yang diteliti berpengaruh positif dan signifikan terhadap kinerja perusahaan, dan secara parsial hanya perspektif proses bisnis internal berpengaruh signifikan terhadap kinerja perusahaan.

\section{B. Saran}

Saran yang dapat disampaikan kepada manajemen Perusahaan Daerah Air Minum Karanganyar dan peneliti selanjutnya adalah sebagai berikut:

1. Bagi peneliti selanjutnya:

a. Diharapkan mampu menambahkan indikator-indikator pernyataan atau intensifikasi/ekstensifikasi dalam masing-masing variabel yang mampu mengarah kedalam permasalahan yang diteliti agar hasil dapat berpengaruh signifikan.

b. Peneliti harus lebih dapat menyeleksi objek yang akan diteliti karena mempengaruhi hasil dari penelitian dan bukan merupakan perusahaan yang mendominasi suatu produk dalam suatu wilayah.

2. Bagi manajemen Perusahaan Daerah Air Minum Karanganyar, berdasarkan penelitian dari masing-masing variabel independen:

a. Perpektif keuangan: penulis menyarankan untuk meningkatkan kinerja keuangan dengan pengendalian biaya operasional, mengelola aset perusahaan yang efektif.

b. Perspektif pelanggan: masih perlu adanya peningkatan atas kepuasan pelanggan, dengan cara meningkatkan kualitas pelayanan sumber daya manusia dan kualitas air yang jernih, serta upaya untuk mempertahankan pelanggan lama. 
c. Perspektif proses bisnis internal: perlu melakukan peningkatan pengelolaan administrasi dan pelayanan secara on-line dan keuangan dengan menggunakan sistem komputerisasi, serta pelayanan penawaran produk melalui media internet.

d. Perspektif pembelajaran dan pertumbuhan: Perusahaan selalu berusaha melakukan komunikasi kerja yang baik dalam pengambilan keputusan, pendelegasian tugas, dan kerjasama dengan karyawan. Manajemen juga harus memperhatikan kinerja karyawan dengan melakukan pelatihan kerja yang berkesinambungan.

e. PDAM mencoba menggunakan Balanced Scorecard sebagai pengukuran kinerja agar pengukuran kinerja lebih lengkap dan menyeluruh, serta mengevaluasi kualitas PDAM dengan menggunakan metode yang lebih baik missal dengan menggunakan konsep Balanced Scorecard, semua perspektif dibahas dengan lebih detail dan terukur dan dilakukan dalam waktu yang berbeda sehingga dapat diketahui terjadi peningkatan atau penurunan dalam pemberian pelayanan.

\section{DAFTAR PUSTAKA}

Arikunto, Suharsimi, 2006, Prosedur penelitian; Suatu Pendekatan Praktek, Bandung: Renika Cipta

Asmaryani, Esi (2006) Balanced Scorecard: Penilaian Kinerja Dengan PendekatanBalanced Scorecard; Skripsi, Fakultas Ekonomi UNS Surakarta.

Ferdinan, Efraim (1998). Balanced Scorecard: Suatu Sistem Pengukuran Kinerja Strategik. Kajian Bisnis, Noor 13 Januari-April

Garisson\&Norren, 2000. Akuntansi Manajemen. Salemba Empat

Ghozali, Imam, 2003, Aplikasi Analisis Multivariat Dengan Program SPSS, Semarang: Badan Penerbit Universitas Diponegoro

Gujarati, Damodar dan ZainSumarno, 1995, EnkometrikaDasar. Erlangga, Yakarta

Gunawan, Barbara (2000) BalancedScorecard: PerspektifBaruDalamMenilaiKinerjaOrganisasi. JurnalAkuntansi dan Investasi

Handoko, Hani dkk,2005, StrategiOrganisasi, Amara Books, Yogyakarta.

Helfert, Erich. A, 1996, TeknikAnalisisKeuangan (PetunjukPraktisUntukMengelola dan MengukurKinerjaPerusahaan), Edisi 8, Jakarta: Erlangga

Indriyati (2008). AnalisisPengaruhPerspektifPerspektifBalancedScorecardTerhadapKinerjaperusahaan, Skripsi, JurusanAkuntansi STIE AUB Surakarta

Kaplan, RS\& Norton, D.P (1996).The Balanced Scorecard: Translating Strategy Intoaction. Boston: Harvard Business School Press

Kuncoro, MudjaratPh.D (2002). Metode Riser UntukBisnisdanEkonomi. Jakarta: Erlangga 
Excellent : Jurnal Manajemen, Bisnis dan Pendidikan

ISSN : 1979-2700

Vol 7, No 1 (2020) ; p.25-36; https://e-journal.stie-aub.ac.id/index.php/excellent

MulyadidanJohnySetyawan, 1999, SistemperencanaandanPengendalianManajemen, Yogyakarta: Aditya Media

Mulyadi, 1999, Strategic Manajement System DenganPendekatan Balanced Scorecard. (Bagianpertamadariduatulisan), Usahawan

Santoso, Singgih, 2002, SPSS Versi 10; Mengolah Data StatistikSecaraProfesional, Jakarta: Elex Media Komputindo

Setiono (2004).AnalisisPengukuranKinerja Perusahaan DenganKonsep Balanced Scorecard, Skripsi, FakultasEkonomi UNS Surakarta

Soetjipto, Budi W, 1997, MengukurKinerjaBisnisDengan Balanced Scorecard, Usahawan

Subagyo, PangestudanDjarwanto Ps, 2005, StaistikaInduktif, Edisi 5, Yogyakarta: BPFE-UGM

Suharyadi dan Purwanto S.K (2006). Statistika Untuk Ekonomi dan Keangan Modern.Salemba Empat 